\title{
Genotype Assignments in a Family with the Pseudo Arylsulfatase A Deficiency Trait without Metachromatic Leukodystrophy
}

\author{
HAYATO KIHARA, WILLIAM E. MEEK, AND ARVAN L. FLUHARTY \\ University of California, Los Angeles, School of Medicine, Mental Retardation Research Center Group at \\ Lanterman State Hospital, Pomona, California 91769
}

\begin{abstract}
Summary
Two children in a family with five siblings were investigated because of low levels of fibroblast arylsulfatase A activity. Neither child had metachromatic leukodystrophy (MLD) and they were diagnosed as having benign pseudo arylsulfatase A deficiency trait (PD). Analysis of arylsulfatase A subunit profiles in fibroblasts provided data for genotype assignments for each family member. Father and mother were assigned an $n / p d$ and $n /$ mld phenotype, respectively. The low enzyme siblings were both assigned $\mathrm{pd} / \mathrm{mld}$; two of the three normal enzyme siblings were assigned an $\mathrm{n} / \mathrm{n}$ phenotype and one an $\mathrm{n} / \mathrm{mld}$.
\end{abstract}

\section{Abbreviations}

MLD, metachromatic leukodystrophy PD, pseudo arylsulfatase A deficiency $\mathbf{N}$, normal

We recently described a family ( $\mathrm{H}$ family) with five siblings, two of whom had very low levels of arylsulfatase A near the range prevalent in MLD (2). The younger of the low enzyme sibs, HII-5, was affected with neurologic disability not typical for MLD, while the other low enzyme sib, HII-2, was healthy with a normal developmental history. It was proposed that neurologic problems of the younger sib were a fortuitous association not related to diminished arylsulfatase $\mathrm{A}$ activity. It was further proposed that the two sibs had some form of the benign PD trait, but whether their genotypes might be $p d / p d$ or $p d / m l d$ could not be ascertained because there was no evidence for MLD in the family. Subsequently, we observed by sodium dodecyl sulfatepolyacrylamide gel electrophoresis and immunoradiochemical nitrocellulose blot radiography that subunits of arylsulfatase A from fibroblasts with the $p d / m l d$ genotype were smaller than subunits of enzyme from normal $(n / n)$ fibroblasts (1). Normal enzyme contained two subunits in the 63- and 59-kD range. There appeared to be more of the larger species which yielded a broad diffuse band while the smaller species yielded a tight crisp band. The $\mathrm{pd} / \mathrm{mld}$ enzyme also contained two subunits, but they

Received December 2, 1983; accepted March 19, 1984.

Requests for reprints should be addressed to $\mathrm{H}$. Kihara, Lanterman State Hospital, P.O. Box 100-R, Pomona, CA 91769.

This study was supported by National Institutes of Health Grants NS-11665 and HD-4612. were in the greater than 59- and 56-kD range. There also appeared to be more of the larger species, but it was not as diffuse as the larger subunit of the normal enzyme. MLD fibroblasts gave no detectable bands in this subunit region. Thus, it appeared that genotype assignments might be made in the $\mathrm{H}$ family by subunit analysis of fibroblast arylsulfatase A.

\section{SUBUNIT PROFILES}

Subunit profiles of fibroblast arylsulfatase A were taken for each member of the $\mathrm{H}$ family (Fig. 1). The two low enzyme sibs (lanes HII-2 and HII-5) showed two subunit bands with migration rates identical with the bands of the $p d / m l d$ genotype, suggesting the same genotype. The mother's subunits (lane HI2) were identical in migration rates and relative amounts as the subunits of a known $n / m l d$ subject. In contrast, the father (lane $H I-1$ and enlarged inset) showed three subunit bands, two strong bands at 63 and $59 \mathrm{kD}$ and a weaker band at $56 \mathrm{kD}$. This is the banding pattern in terms of both migration rates and relative amounts expected of a carrier of the $p d$ allele. The father was therefore assigned the $n / p d$ genotype. Carriers of PD or MLD would be expected to have arylsulfatase A activity in the halfnormal range which was the case for both the father and mother (2). Enzyme activity of one of the other sibs was also in the heterozygote range. His subunit profile (lane HII-1) was like that of his mother, indicating a $n / m l d$ genotype. The two remaining sibs had normal enzyme activities, and their enzyme subunit profiles (lanes HII-3 and HII-4) were also normal. They were assigned $n / n$ genotypes. The previously depicted $\mathrm{H}$ family pedigree can now be modified as shown in Fig. 2.

The parental and sibling genotype assignments are consistent with observed enzyme activities and they provide an explanation for the appearance of the PD trait in HII-2 and HII-5. However, whether PD is indeed benign or has some relationship to the neurologic defects in HII-5 is still moot.

\section{REFERENCES}

1. Fluharty AL, Meek WE, Kihara H 1983 Pseudo arylsulfatase A deficiency: evidence for a structurally altered enzyme. Biochem Biophys Res Commun 112:191

2. Hreidarsson SJ, Thomas GH, Kihara H, Fluharty AL, Kolodny EJ, Moser HW, Reynolds LW 1983 Impaired cerebroside sulfate hydrolysis in fibroblasts of sibs with "pseudo" arylsulfatase A deficiency without metachromatic leukodystrophy. Pediatr Res 17:701

3. Kihara H, Fluharty AL, Ng WG, Leider W 1982 Presymptomatic diagnosis: metachromatic leukodystrophy or pseudo arylsulphatase A deficiency? J Inher Metab Dis 5:215-217 

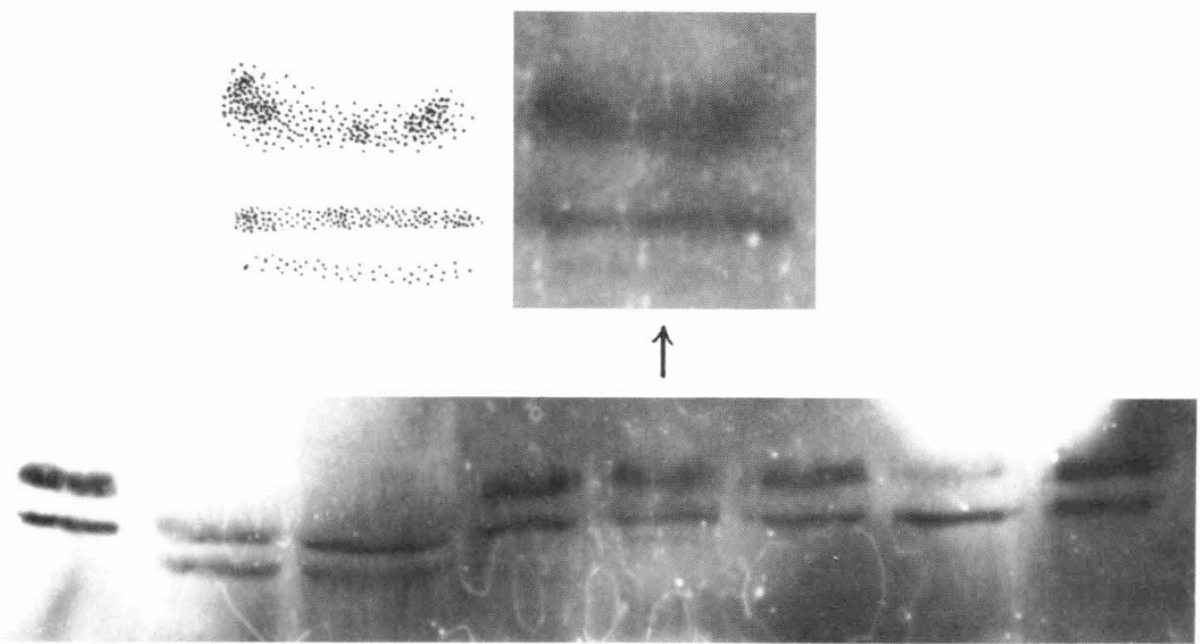

$\mathrm{n} / \mathrm{n} \mathrm{pd} / \mathrm{mld} \mathrm{H} I-2 \mathrm{H} \amalg-3 \quad \mathrm{HI}-1 \mathrm{HI}-2 \mathrm{n} / \mathrm{mld} \mathrm{n} / \mathrm{n}$

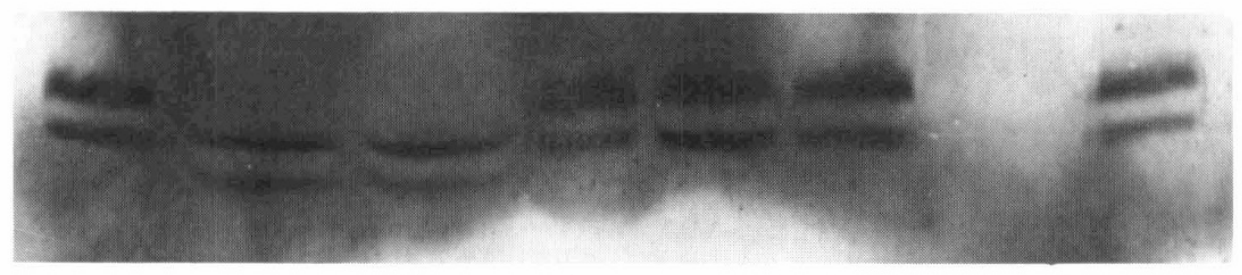

$\mathrm{n} / \mathrm{n} \quad \mathrm{pd} / \mathrm{mld} \mathrm{H} \Pi-5 \mathrm{H} \Pi-4 \mathrm{n} / \mathrm{mld} \mathrm{H} \Pi-1 \mathrm{mld} / \mathrm{mld} \mathrm{n} / \mathrm{n}$

Fig. 1. Subunit banding patterns of fibroblast arylsulfatase A from members of the $\mathrm{H}$ family. Members of another family, the $\mathrm{S}$ family described previously (3), were used as controls for the following genotypes: the father as $\mathrm{pd} / \mathrm{mld}$; the mother as $\mathrm{n} / \mathrm{mld}$; and the proband as $\mathrm{mld} / \mathrm{mld}$. Fibroblast extracts were subjected to DEAE-cellulose chromatography and aliquots containing 0.5 unit of arylsulfatase A were carried through sodium dodecyl sulfate-polyacrylamide gel electrophoresis and immunoradiochemical nitrocellulose blot radiography as described (1). There were three types of cells and the amount of protein applied for each type was: $36-45 \mu \mathrm{g}$ for full enzyme activity cells, $n / n$, HII-3 and HII-4; $60-95 \mu \mathrm{g}$ for half-normal activity cells, $n / \mathrm{mld}$, HI-1, HI-2, and HII-1; 340-582 $\mu$ g for cells with less than $10 \%$ of normal activity, pd/mld, mld/mld, HII-2, and HII-5. Photographic reproduction of radioautographs did not allow satisfactory visualization of subunit bands. Therefore, the immunoradiochemical treated nitrocellulose sheets were further treated with goat anti-rabbit IgG horseradish peroxidase conjugate using the Immuno-Blot (GAR-HRP) assay kit (Bio-Rad). Color development with horseradish peroxidase substrate as specified by the manufacturer yielded bands which were more amenable to photography.

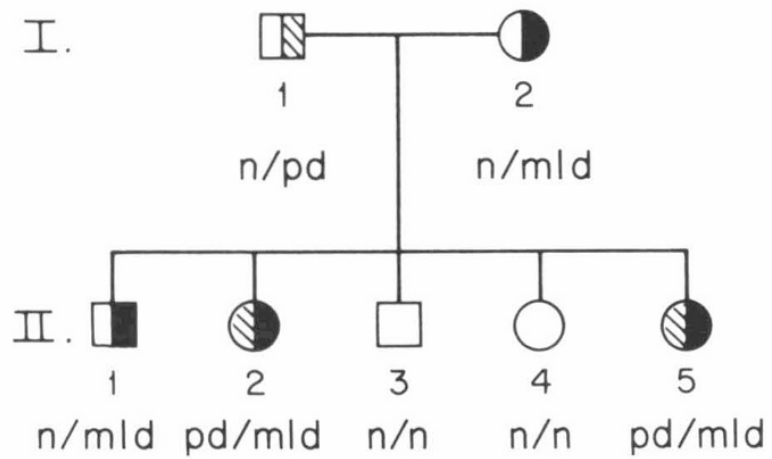

Fig. 2. Modified pedigree of $\mathrm{H}$ family. Dark shading represents $m l d$ gene and hatched shading represents $p d$ gene. 